\title{
Bounds for the generalized Lupaş functional
}

\author{
HACÈNE BELBACHIR and MOURAD RAHMANI
}

\section{ABSTRACT.}

Upper and lower bounds for the generalized Lupaş functional of $n$-convex ( $n$-concave) functions are given.

\section{USTHB}

FACULTY OF MATHEMATICS

Po. Box 32, El Alia, 16111, Algiers, Algeria

E-mail address: hacenebelbachir@gmail.com, hbelbachir@usthb.dz

\section{USTHB}

FACULTY OF MATHEMATICS

Po. Box 32, El Alia, 16111, Algiers, Algeria

E-mail address: mrahmani@usthb.dz 